\title{
Pengembangan Media Pop-up Book Materi Kingdom Animalia untuk Siswa Sekolah Menengah Pertama
}

\author{
Author(s): Dwi Mungallamah, \& Much Fuad Saifuddin \\ Editor: Anastasia Dewi Anggraeni \\ Publication details, including author guidelines \\ URL: https://jlis.idcounselor.com/index.php/jlis/about/submissions
}

\author{
Article History \\ Received: $1 / 21 / 2021$ \\ Revised: $3 / 6 / 2021$ \\ Accepted: 4/7/2021
}

How to cite this article (APA)

Mungallamah, D., \& Saifuddin, M. F. (2021). Pengembangan Media Pop-up Book Materi Kingdom Animalia untuk Siswa Sekolah Menengah Pertama. Journal of Learning and Instructional Studies, 1(1), 25-36. https://doi.org/10.46637/jlis.v1i1.4

The readers can link to article via https://doi.org/10.46637/jlis.v1i1.4

\section{SCROLL DOWN TO READ THIS ARTICLE}

\begin{abstract}
Southeast Asia Mental Health and Counseling Association (as publisher) makes every effort to ensure the accuracy of all the information (the "Content") contained in the publications. However, we make no representations or warranties whatsoever as to the accuracy, completeness, or suitability for any purpose of the Content. Any opinions and views expressed in this publication are the opinions and views of the authors and are not the views of or endorsed by Southeast Asia Mental Health and Counseling Association. The accuracy of the Content should not be relied upon and should be independently verified with primary sources of information. Southeast Asia Mental Health and Counseling Association shall not be liable for any losses, actions, claims, proceedings, demands, costs, expenses, damages, and other liabilities whatsoever or howsoever caused arising directly or indirectly in connection with, in relation to, or arising out of the use of the content.
\end{abstract}

Journal of Learning and Instructional Studies is published by Southeast Asia Mental Health and Counseling Association comply with the Principles of Transparency and Best Practice in Scholarly Publishing at all stages of the publication process. Journal of Learning and Instructional Studies also may contain links to web sites operated by other parties. These links are provided purely for educational purpose.

\section{(c) (i)}

This work is licensed under a Creative Commons Attribution 4.0 International License.

Copyright by Mungallamah, D., \& Saifuddin, M. F. (2021)

The author(s) whose names are listed in this manuscript declared that they have NO affiliations with or involvement in any organization or entity with any financial interest (such as honoraria; educational grants; participation in speakers' bureaus; membership, employment, consultancies, stock ownership, or other equity interest; and expert testimony or patent-licensing arrangements), or non-financial interest (such as personal or professional relationships, affiliations, knowledge or beliefs) in the subject matter or materials discussed in this manuscript. This statement is signed by all the authors to indicate agreement that the all information in this article is true and correct. 


\title{
Pengembangan Media Pop-up Book Materi Kingdom Animalia untuk Siswa Sekolah Menengah Pertama
}

\author{
Dwi Mungallamah, \& Much Fuad Saifuddin* \\ Universitas Ahmad Dahlan, Yogyakarta, Indonesia.
}

\begin{abstract}
This research tries to verify the feasibility of the pop-up book media on the substance of the kingdom animalia group of invertebrates. This research is a development research with a 4D model (Define, Design, Develope, Disseminate). Data collected through research instruments for material experts, media experts, science teacher assessments, and student response surveys in Junior High Schools. The results of the feasibility amount of the media expert with an average of $85.8 \%$ were stated very feasible. The results of the feasibility value of the material expert with an average value of $63.8 \%$ were claimed feasible. The results of the assessment with a science teacher with an average value of $95.25 \%$ were confirmed very feasible. The trials were carried out by small group trials and large group trials. The results of the feasibility trial in the small group with an average of $98.66 \%$ which is stated to be very feasible; while the large group trial with an average of $92.91 \%$ with a very feasible category. These findings prove that the pop-up book media is reported to be worthy of being a learning medium adopted in learning activities.
\end{abstract}

Key Words: Pop-up book; 4D; Kingdom animalia; Avertebrata; Junior High Schools

Abstrak: Penelitian ini bertujuan untuk mengetahui kelayakan media pop-up book pada materi kingdom animalia kelompok avertebrata. Penelitian ini merupakan penelitian pengembangan dengan model 4D (Define, Design, Develope, Disseminate). Data yang diperoleh melalui instrumen penelitian untuk ahli materi, ahli media, penilaian guru IPA, dan angket respon siswa Sekolah Menengah Pertama. Hasil nilai kelayakan dari ahli media dengan rata-rata $85,8 \%$ yang dinyatakan sangat layak. Hasil nilai kelayakan dari ahli materi dengan nilai rata-rata 63,8\% yang dinyatakan layak. Hasil penilaian dengan guru IPA dengan nilai rata-rata 95,25\% dinyatakan sangat layak. Uji coba dilakukan dengan uji coba kelompok kecil dan uji coba kelompok besar. Hasil uji coba kelayakan pada kelompok kecil dengan rata-rata sebesar 98,66\% yang dikatakan sangat layak; sedangkan uji coba kelompok besar dengan rata-rata sebesar 92,91\% dengan kategori sangat layak. Temuan ini menunjukkan bahwa media pop-up book dikatakan layak menjadi media pembelajaran yang digunakan dalam kegiatan pembelajaran.

Kata Kunci: Pop-up Book; 4D; Kingdom animalia; Avertebrata; Sekolah Menengah Pertama

\footnotetext{
* Corresponding author: Much Fuad Saifuddin. Universitas Ahmad Dahlan. Kragilan, Tamanan, Banguntapan, Bantul Regency, Special Region of Yogyakarta 55191, Indonesia. Email: fuad.saifuddin@pbio.uad.ac.id
} 


\section{Pendahuluan}

Materi yang dianggap paling sulit oleh para guru Ilmu Pengetahuan Alam (IPA) terletak pada materi Klasifikasi Makhluk Hidup (KMH). Alasannya adalah cakupan materi yang luas, kesulitan dalam memahami bahasa latin, sulit dalam menentukan peranan, pengklasifikasian dan mendeskripsikan ciri-ciri dari masing-masing filum serta waktu pembelajaran yang disediakan terbatas (Aprianty, Yeni, dan Wahyuni, 2016). Media pembelajaran adalah komponen sumber belajar atau wahana fisik yang mengandung materi instruksional yang dapat merangsang peserta didik untuk belajar. Media memiliki fungsi yang jelas yaitu memperjelas, memudahkan dan membuat menarik materi yang akan disampaikan oleh guru kepada peserta didik (Khoirotun, Fianto, \& Riqqoh, 2014). Kesulitan yang dialami siswa dikarenakan pembahasannya yang cukup komplit, menggunakan nama-nama KMH sehingga membuat siswa kesulitan untuk mengingatnya. Ketersediaan sumber dan media belajar dan juga beberapa faktor internal dari siswa dipercaya mempengaruhi situasi ini. Persepsi siswa menganggap bahwa KMH sebagai materi yang harus dihafal, namun siswa mengalami kesulitan untuk menghafal materi pelajaran tersebut (Henno \& Reiska, 2010). Ada persoalan bagi siswa dalam membedakan hewan Vertebrata daripada Invertebrata. Alasannya, karena susah dihafal dan banyak menggunakan bahasa latin. Bahkan tidak sedikit dari mereka yang masih kesusahan dalam membedakan hewan Vertebrata dan Invertebrata. Hal ini membuktikan bahwa kemampuan siswa dalam mengklasifikasikan Kingdom Animalia Invertebrata masih rendah, sehingga mempengaruhi tercapainya tujuan dari kompetensi dasar pada materi tersebut (A'yun dan Erman, 2019).

Masa peralihan materi IPA yang lebih kompleks dari jenjang Sekolah Dasar (SD) ke Sekolah Menengah Pertama (SMP) membutuhkan adaptasi dengan cara belajar ke jenjang yang lebih tinggi sehingga diperlukan media yang lebih menunjang pemahaman materi dan menarik siswa dalam kegiatan pembelajaran. Jika media yang digunakan oleh guru seadanya, seperti buku paket dan/atau PPT (Power point) dan media yang sudah disediakan oleh sekolah, maka siswa kurang mendapatkan media pembelajaran yang variatif yang membuat siswa pasif dalam kegiatan pembelajaran. Sehingga dibutuhkan suatu media pembelajaran yang mengaktifkan siswa, yaitu dengan media pembelajaran Pop-up Book.

Berdasarkan hasil observasi kelas VII dan wawancara dengan guru IPA yang dilakukan di SMP Muhammadiyah 2 Yogyakarta diperoleh informasi bahwa guru pada saat mengajar menggunakan media pembelajaran PPT (Power Point) yang terlalu banyak tulisan dan buku paket IPA yang membuat siswa pasif dan kurang bersemangat dalam pembelajaran, sehingga siswa ingin mendapatkan media yang menarik dan membuat siswa senang dan bersemangat dalam pembelajaran. Pemilihan materi Kingdom Animalia pada kelompok Avertebrata didasarkan pada hasil wawancara dengan guru IPA bahwa materi Kingdom Animalia untuk kelompok Vertebrata guru sudah mempunyai media yaitu berupa kartu hewan; sedangkan untuk kelompok Avertebrata guru belum mempunyai media. Atas dasar itu peneliti memutuskan untuk memilih kelompok Avertebrata dijadikan sebagai materi di dalam pop-up book yang dapat memvisualisasikan gambar secara nyata agar dapat merangsang daya ingat siswa dan dapat memvisualisasikannya gambar yang jelas dan detail sehingga materi dapat tersampaikan dengan baik. Pengembangan media pembelajaran pop-up book pada materi kingdom animalia bertujuan untuk memudahkan siswa belajar dalam proses pembelajaran terutama pada materi Kingdom Animalia dan mengetahui apakah media pop-up book layak dijadikan media pembelajaran di kelas. Salah satu media belajar yang dapat digunakan dalam pembelajaran yaitu media pop-up book. Pop-up adalah bentuk menarik dari seni kertas yang membentuk struktur tiga dimensi saat dibuka dan struktur dua dimensi ketika ditutup (Iizuka, 2011).

Journal of Learning and Instructional Studies (2021), 1(1), 25-36

https://doi.org/10.46637/jlis.v1i1.4 
Pop-up book yang dikembangkan dalam penelitian pengembangan ini dirancang untuk siswa SMP kelas VII pada materi Kingdom Animalia kelompok Avertebrata dengan karakteristik ukuran pop-up book yang mudah dibawa dan mudah disimpan, gambar yang disajikan muncul/timbul ketika dibuka tiap halamanya. Pada materi dilengkapi contoh gambar spesies dengan nama ilmiah dan dilengkapi dengan petunjuk penggunaan dan petunjuk penyimpanan. Tujuan dilakukannya pengembangan media pop-up book pada materi Kingdom Animalia untuk mengetahui apakah media pop-up book layak digunakan sebagai media pembelajaran dalam kegiatan pembelajaran. Media memiliki fungsi yang jelas yaitu memperjelas, memudahkan dan membuat menarik materi yang akan disampaikan oleh guru kepada peserta didik sehingga dapat memotivasi belajarnya dan mengefisienkan proses belajar (Mawarni, 2014)

Keunggulan dari pop-up book yaitu dapat memvisualisasikan gambar menjadi lebih menarik. Pop-up book dapat digunakan sebagai bahan ajar siswa secara individu maupun secara berkelompok dan pop-up book bersifat praktis dan dapat menambah semangat serta minat siswa dalam belajar karena dapat memvisualisasikan konsep dalam pelajaran kedalam bentuk gambar 3 dimensi (Masturah, 2018). Buku Pop-Up dipilih sebagai alternatif media yang dikembangkan karena buku Pop-Up merupakan salah satu bidang kreatif dari paper dengan movable book dan lift the flap. Hal inilah yang menjadikan Pop-Up lebih mudah diingat (Shita Dkk, 2013). Media belajar pop-up book dianggap mempunyai daya tarik tersendiri bagi peserta didik karena mampu menyajikan visualisasi dengan bentuk-bentuk yang dibuat dengan melipat, bergerak dan muncul sehingga memberikan kejutan dan kekaguman bagi peserta didik ketika membuka setiap halamannya (Khoirotun, 2014). Kelebihan dari media Pop Up Book adalah memberikan pengalaman khusus pada pembaca karena melibatkan pembaca dalam cerita tersebut seperti menggeser, membuka. Hal ini akan membuat kesan tersendiri akan lebih mudah masuk kedalam ingatan ketika menggunakan media pop-up book (Setyawan, 2014).

\section{MetOde}

Penelitian yang dilakukan merupakan penelitian $R \& D$ (Research and development). Penelitian dengan mengembangkan media pop-up book. Penelitian ini dilakukan dilakukan secara online menggunakan link google form. Subjek penelitian yang dilakukan yaitu dengan uji coba kelompok kecil sebanyak 11 siswa dan uji coba kelompok besar sebesar 32 siswa. Prosedur penelitian pengembangan menggunakan model 4D (Define, Design, Develop, Disseminate). Instrumen pengumpulan data yang digunakan pada penelitian pengembangan ini menggunakan instrumen penelitian validator (ahli media, ahli materi) guru IPA dan angket respon siswa SMP. Teknik analisis data yang diperoleh dalam penelitian ini dianalisis dengan menggunakan data deskriptif. Data tersebut merupakan data kuantitatif yang diubah dari penilaian skor menjadi kategori dalam mengetahui kualitas kelayakan media pop-up book.

Penelitian yang dilakukan menggunakan instrumen yang mengacu pada skala likert dan skala guttman. Skala likert diperuntukan untuk 2 validator yaitu ahli media dan ahli materi sedangkan skala guttman untuk guru IPA dan siswa. Tahap-tahap yang dilakukan peneliti dalam melakukan pengembangan media pop-up book menggunakan model 4D (Design, Define, Develop, Disseminate) (Thiagarajan, Semmel, \& Semmel, 1974) yaitu sebagai berikut:

1. Tahap define (pendefinisian)

Peneliti melakukan analisis kurikulum dengan menentukan KD (kompetensi dasar) dan KI (kompetensi inti), Indikator pencapaian kompetensi, dan menentukan tujuan pembelajaran, 
2. Tahap design (perancangan)

Tahap yang dilakukan peneliti yaitu menentukan unsur-unsur yang diperlukan dalam pembuatan media pop-up book yaitu:

a. Menyusun instrumen yang diadaptasi dari Skripsi Elna Rahmah dengan judul 'Pengembangan Media Pop-up Bersuara Pada Mata Pelajaran Biologi Materi Ekosistem Kelas X Sekolah menengah Atas" yang disesuaikan dengan karakteristik media pop-up book pada materi kingdom animalia untuk siswa SMP Kelas VII.

b. Pemilihan bentuk penyajian media pop-up book

c. Spesifikasi produk yang dikembangkan yaitu:

a) Tampilan media Pop-up Book, cover menggunakan gambar pemandangan bawah laut dan menggunakan kertas ivory yang dilapisi kertas karton sedangkan untuk isi halaman Pop-up Book menggunakan kertas ivory. Pop-up Book berukuran 32,5 x $48 \mathrm{~cm}$.

b) Bagian media pembelajaran Pop-up Book yang di kembangkan meliputi: Cover Avertebrata, daftar isi, petunjuk penggunaan dan petunjuk penyimpanan, peta konsep, KI 3 dan KD 3.2, tujuan kegiatan, materi pengantar kingdom animalia, dan materi pengantar avertebrata, materi pokok avertebrata diantaranya porifera, coelenterata, plathyhelminthes, nemathelminthes, annelida, mollusca, arthropodha, dan echinodermata, daftar pustaka dan biodata penulis.

c) Bagian pendukung media Pop-up Book yaitu alat evaluasi (LKS).

3. Tahap develop (pengembangan)

Hasil dari tahap develop (pengembangan) media pop-up book dilakukan dengan 2 tahap kegiatan yaitu expert appraisal dan development testing (Thiagarajan, Semmel, dan Semmel):

a. Expert appraisal tahap yang dilakukan yaitu pengujian media pembelajaran pop-up book oleh validator dan guru IPA menggunakan instrumen penelitian yang telah dibuat di tahap design

b. Developmental testing merupakan tahap uji coba produk media pembelajaran pop-up book.

4. Tahap disseminate (penyebarluasan)

Tahap yang dilakukan yaitu menyebarluaskan media pop-up book yang telah dikembangkan. Analisis persentase kelayakan media pembelajaran pop-up book untuk ahli media dan ahli materi menggunakan rumus sebagai berikut:

$$
\text { kelayakan: } \frac{\text { skor yang diperoleh }}{\text { skor maksimal yang diperoleh }} \times 100 \%
$$

Sedangkan analis persentase kelayakan media pop-up book menurut respon siswa yaitu:

Keterangan :

$$
P: \frac{f}{n} x 100 \%
$$

$\mathrm{P}=$ Nilai media

$\mathrm{F}=$ Jumlah nilai total "Ya"

$\mathrm{N}=$ Jumlah indikator keseluruhan (Sugiyono, 2016)

Journal of Learning and Instructional Studies (2021), 1(1), 25-36 
Tabel 1. Pedoman rentang skor kualitas media pop-up book

\begin{tabular}{lll}
\hline Rentang skor & Kategori & Dikonversikan \\
\hline $75 \%-100 \%$ & Sangat baik & Sangat layak \\
$56-75 \%$ & Baik & Layak \\
$40-55 \%$ & Cukup baik & Cukup layak \\
$0-39 \%$ & Kurang baik & Kurang layak \\
\hline
\end{tabular}

(Sugiyono, 2016)

\section{Hasil dan Pembahasan}

Berdasarkan hasil uji kelayakan media pembelajaran pop-up book pada materi kingdom animalia yang telah dilakukan peneliti sudah melakukan tahap dengan menggunakan model 4D (design, define, develop, disseminate) sebagai berikut:

1. Tahap Define (pendefinisian)

Tahap define peneliti sudah melewati tahapan analisis diantaranya:

a. Analisis kurikulum : Hasil yang diperoleh peneliti yaitu menentukan KD (Kompetensi Dasar), KI (Kompetensi Inti), Indikator pencapaian dan menentukan Tujuan Pembelajaran. Berdasarkan hasil wawancara yang telah dilakukan dengan guru IPA mengenai analisis kurikulum yang telah dilakukan yaitu pada KD 3.2 Mengklasifikasikan makhluk hidup dan benda berdasarkan karakteristik yang diamati. Pemilihan materi pada kingdom animalia kelompok avertebrata.

b. Analisis kebutuhan: Hasil yang diperoleh dari wawancara dengan guru IPA yaitu ditentukan media pembelajaran yang perlu dikembangkan untuk kebutuhan siswa yaitu dengan engembangkan media pop-up book.

c. Analisis karakteristik siswa : Hasil yang diperoleh yaitu agar media pop-up book yang dikembangkan sesuai dengan karakteristik siswa SMP kelas VII karena hasil dari analisis karakteristik siswa tersebut cenderung pasif kurang bersemangat dalam kegiatan pembelajaran.

d. Menentukan tujuan pembelajaran: Hasil yang diperoleh yaitu : Siswa dapat mengetahui ciri-ciri dari setiap phylum, Siswa dapat mengamati karakteristik dari setiap phylum, Siswa dapat mengklasifikasikan ciri-ciri dari setiap phylum.

2. Tahap Design (perancangan)

Peneliti merancang media pop-up book dan menyusun instrumen penelitian yang digunakan untuk menilai kelayakan media pembelajaran pop-up book. Instrumen dirancang untuk validator yaitu ahli media dan ahli materi dengan menggunakan skala likert dan instrumen untuk guru IPA serta angket respon siswa menggunakan skala guttman. adapun spesifikasi produk media yang dikembangkan yaitu:

a. Tampilan media pop-up book: media pembelajaran pop-up book pada materi kingdom animalia kelompok avertebrata ditujukan untuk siswa SMP kelas VII.

b. Bagian pada media pop-up book yang dikembangkan meliputi: cover avertebrata, daftar isi, petunjuk penggunaan, petunjuk penyimpanan, peta konsep, $\mathrm{KI}$ dan KD 3.2, tujuan kegiatan.

c. Penyusunan LKS 


\section{Tahap Develop (pengembangan)}

Tahap pengembangan dimana media pop-up book yang dikembangkan diuji kelayakannya dengan memvalidasi produk menggunakan instrumen penelitian. Hal ini sesuai dengan (Irwan, Santyasda, \& Tegeh, 2014), tahap pengembangan adalah tahap dimana semua bahan atau komponen yang terkumpul baik dari tahap define dan desain dikumpulkan menjadi satu dan diubah kedalam bentuk media yang siap pakai dan setelah selesai kemudian dilakukan proses validasi media pop-up book. Tahap pengembangan merupakan tahap Implementasi untuk menerapkan media pembelajaran yang sudah dibuat. Pada tahap ini semua yang telah dikembangkan diset sedemikian rupa agar bisa diimplementasikan kepada target (Budiarta, 2013). dilakukan oleh 1 dosen ahli media, 1 dosen ahli materi, penilaian media pop-up book oleh 1 guru IPA dan angket respon siswa. Berikut hasil penilaian media pop-up book yang telah diperoleh:

a) Analisis skor instrumen oleh ahli media dilakukan pengujian 2 aspek yaitu aspek penyajian dan aspek kegrafikan aspek penyajian sebesar $85 \%$ dan aspek kegrafikan sebesar $86,6 \%$ dengan rata-rata sebesar 85,8\% dengan kategori "Sangat layak". Nilai aspek tertinggi terdapat pada aspek kegrafikan dengan persentase $86,6 \%$. Hal ini sesuai dengan salah satu pernyataan dengan mendapatkan skor 4 (Sangat layak) "Media popup book menampilkan gambar yang sesuai dan memperjelas materi, yang sesuai dengan hasil penelitian (Zainorrahman, Azizah, \& Kadarisman, 2019) yang menyatakan bahwa "Pernyataan Gambar yang disajikan sesuai dengan materi memperoleh nilai persentase sebesar 99\% dengan kategori sangat baik, Gambar yang disajikan di dalam media merupakan gambar pendukung untuk menekankan pesan yang ingin disampaikan didalam teks/ materi sehingga pesan tersebut mudah diingat dalam waktu yang lama dapat dilihat pada Tabel 2.

Tabel 2. Hasil data kuantitatif media pop-up book oleh ahli media

\begin{tabular}{cccc}
\hline No & Aspek Penilaian & Skor (\%) & Kategori \\
\hline 1 & Aspek penyajian & $85 \%$ & Sangat layak \\
2 & Aspek kegrafikan & $86,6 \%$ & Sangat layak \\
& Rata-rata & $85,8 \%$ & Sangat layak \\
\hline
\end{tabular}

Catatan saran yang diberikan oleh ahli media dilakukan perbaikan sesuai dengan kebutuhan, adapun saran yang diberikan yaitu: Judul diganti menjadi Pop-up Book Avertebrata, bagian nemathelminthes gambar diganti, latar belakang arthropoda kurang sesuai. Hasil perbaikan dapat dilihat pada Gambar 1.

Tampilan cover sebelum direvisi

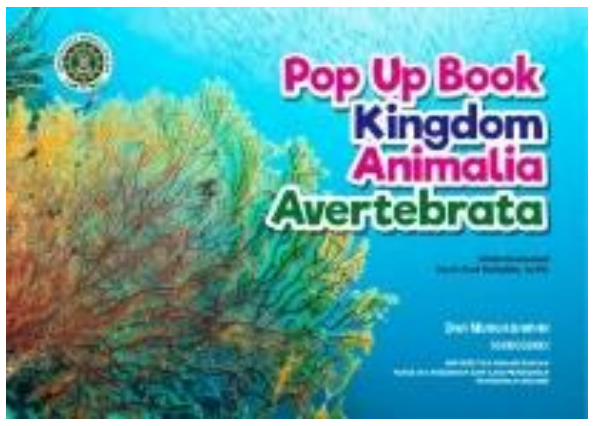

Tampilan background materi nemathelminthes sebelum direvisi
Tampilan cover setelah direvisi

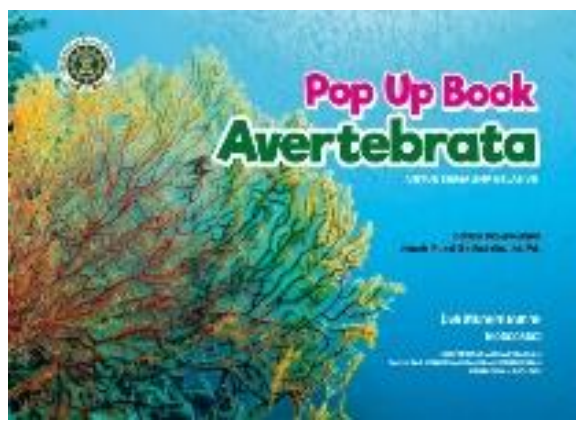

Tampilan background materi nemathelminthes setelah direvisi 

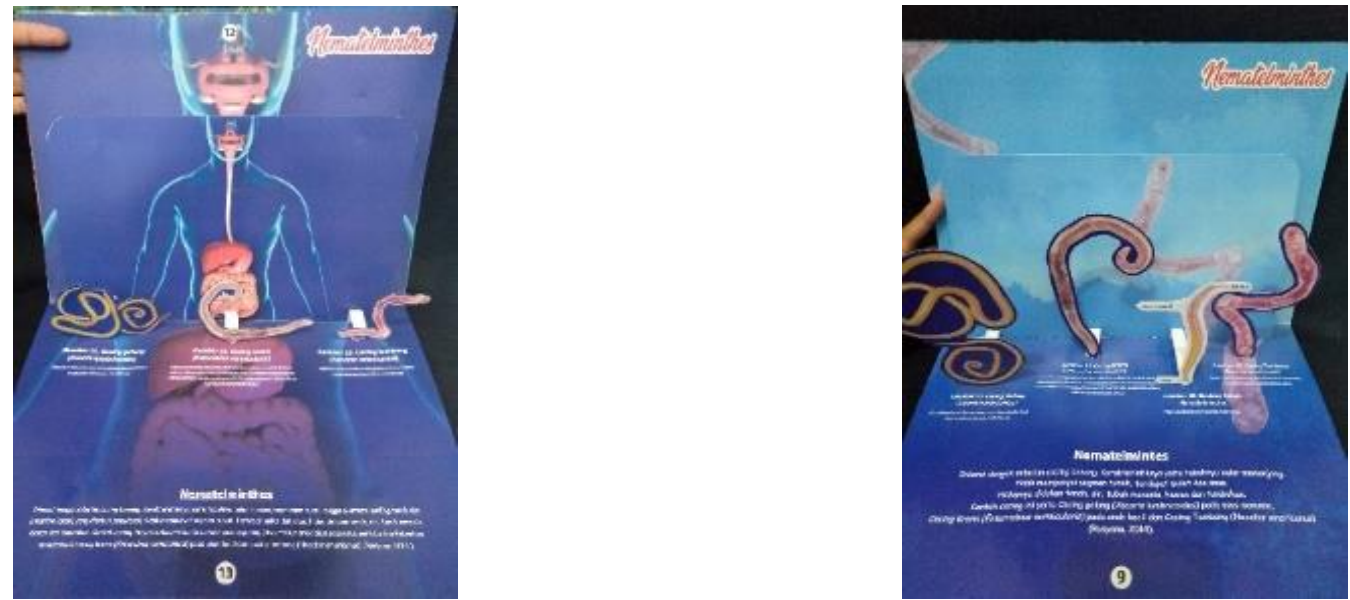

Gambar 1 Tampilan hasil revisi oleh ahli media

b) Analisis skor instrumen oleh ahli materi dengan pengujian 2 aspek kriteria yaitu aspek kelayakan isi sebesar 70\%, dan aspek bahasa dan gambar sebesar 68,75\% dengan rata-rata 69,4\% yang dikategorikan "Layak". Nilai aspek tertinggi terdapat pada aspek kelayakan isi dengan persentase $70 \%$, salah satu pernyataan dengan mendapatkan skor 4 (Sangat layak) "Materi pada media pembelajaran pop-up book tidak memuat unsur-unsur yang merusak moral dan nilai-nilai sosial" dan pernyataan dengan mendapatkan skor 3 (Layak) "Materi pada media pembelajaran Pop-up Book menggunakan bahasa yang sesuai dengan tingkat perkembangan siswa dan mudah dipahami" yang sesuai dengan hasil penelitian (Zainorrahman et al., 2019) yang menyatakan bahwa "Media Pop Up Book memiliki fiture materi yang disusun menggunakan bahasa sederhana dan mudah untuk dipahami, materi juga disertakan gambar sehingga menstimulus siswa untuk membaca dan memahami isi materi"sehingga media pop-up book layak digunakan sebagai media pembelajaran dalam kegiatan pembalajaran.

Hasil data kuantitatif media pop-up book oleh ahli materi dapat dilihat pada Tabel 2.

Tabel 2. Hasil Data Kuantitatif Media Pop-Up Book oleh Ahli Materi

\begin{tabular}{cccc}
\hline No & Aspek Penilaian & Skor (\%) & Kategori \\
\hline 1 & Aspek kelayakan isi & $70 \%$ & \\
2 & Aspek bahasa dan gambar & $68,75 \%$ & Sangat layak \\
& Rata-rata & $69,4 \%$ & Layak \\
\hline
\end{tabular}

Catatan saran yang diberikan oleh ahli media dilakukan perbaikan sesuai dengan kebutuhan, adapun saran yang diberikan yaitu : Peta konsep tidak sesuai dengan KD 3.2, Materi belum menunjukan karakteristik yang bisa diamati (sesuaikan dengan KD). Hasil perbaikan dapat dilihat pada Gambar 2. 
Tampilan peta konsep sebelum direvisi Tampilan peta konsep setelah direvisi

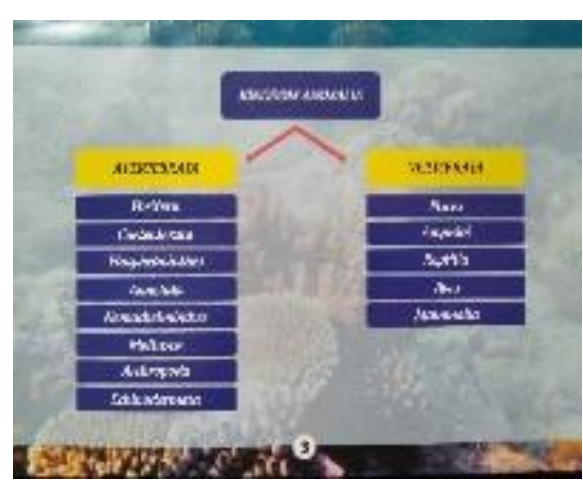

Tampilan materi pokok Porifera setelah direvisi

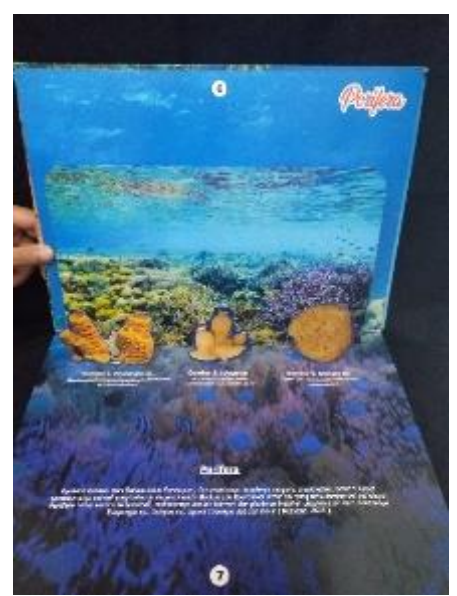

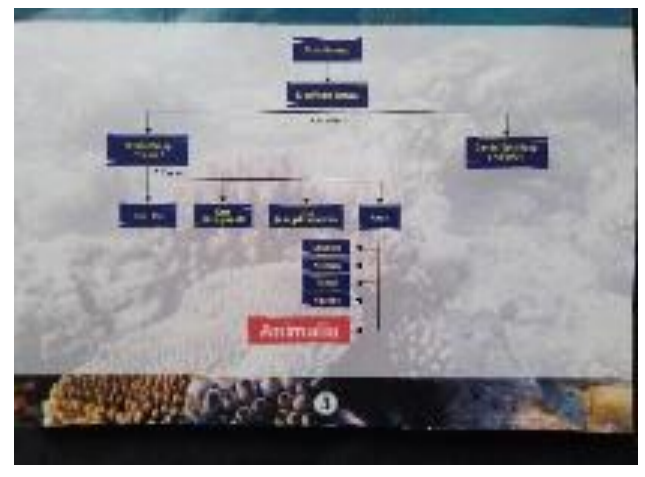

Tampilan materi pokok Porifera setelah direvisi

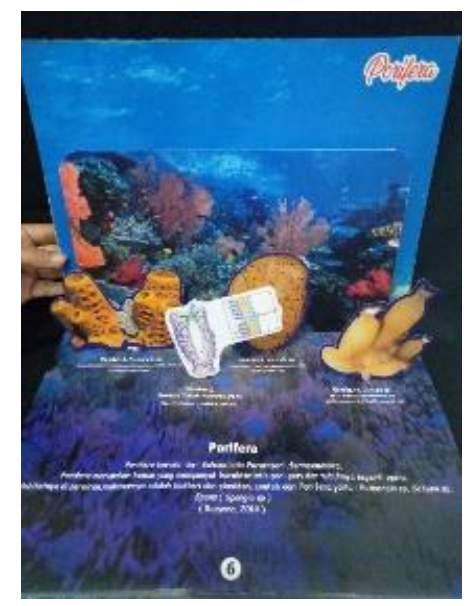

Gambar 2 Tampilan hasil revisi oleh Ahli Materi

c) Analisis skor instrumen oleh guru IPA dengan pengujian 4 kategori aspek yaitu aspek kelayakan isi sebesar $100 \%$, aspek bahasa dan gambar sebesar $100 \%$, aspek penyajian sebesar $100 \%$ dan aspek kegrafisan $81 \%$ dengan rata-rata sebesar 95,25\% dengan kategori "Sangat layak". Nilai aspek tertinggi terdapat pada aspek kelayakan isi, aspek bahasa dan gambar, dan aspek penyajian dengan persentase skor tiap aspek sebesar $100 \%$, hal tersebut sesuai dengan hasil penelitian (Zainorrahman et al., 2019) yang menyatakan bahwa "Media Pop Up Book memiliki daya tarik tersendiri kepada peserta didik karena dapat menyajikan gambar yang mampu memvisualisasikan teks yang ada di dalam media, Setiap penjelasan atau materi yang terdapat di dalam media Pop Up Book memiliki gambar penjelas maupun gambar contoh yang dapat bergerak ataupun gambar yang berdiri, hal ini membuat tampilan media lebih menarik serta menstimulus siswa untuk membaca materi hingga halaman terakhir (Zainorrahman et al., 2019). Kegiatan membaca yang dilakukan oleh siswa merupakan salah satu indikator keaktifan, Media Pop Up Book memiliki fiture materi yang disusun menggunakan bahasa sederhana dan mudah untuk dipahami, materi juga disertakan gambar sehingga menstimulus siswa untuk membaca dan memahami isi materi (Zainorrahman et al., 2019). Hal ini sesuai dengan hasil penelitian (Permana \& Sari, 2018 yang menunjukan bahwa hasil penilaian guru IPA mengenai media pop-up book sebesar 95,5\% yang membuktikan bahwa media pop-up 
book disukai oleh siswa dan layak dijadikan medi pembelajaran. Hasil data kuantitatif media pop-up book oleh guru IPA dapat dilihat pada Gambar 3.

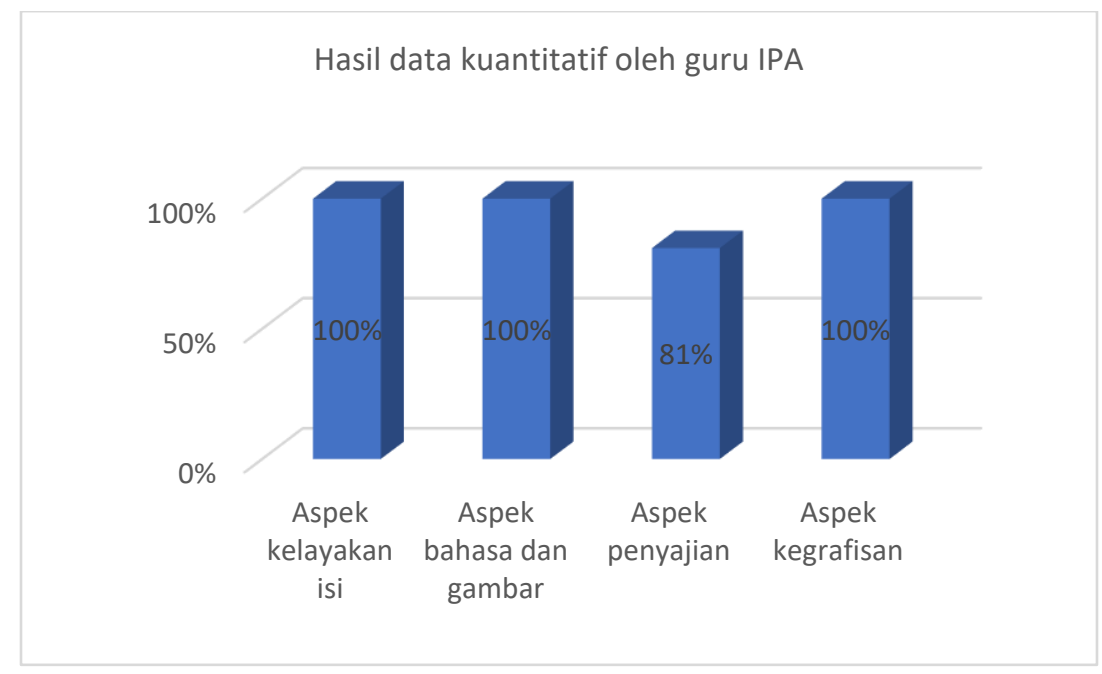

Gambar 3 Hasil data kuantitatif penilaian oleh guru IPA

Catatan saran yang diberikan oleh guru IPA dilakukan perbaikan sesuai dengan kebutuhan, adapun saran yang diberikan, yaitu: Khusus arthropodha gambar bisa menyesuaikan 4 kelas (insecta, arachnidea, crustacea, myriapodha), dan disertai ciri masing-masing kelas. Hasil perbaik dapat dilihat pada Gambar 4.

Tampilan materi pokok Arthropodha sebelum direvisi

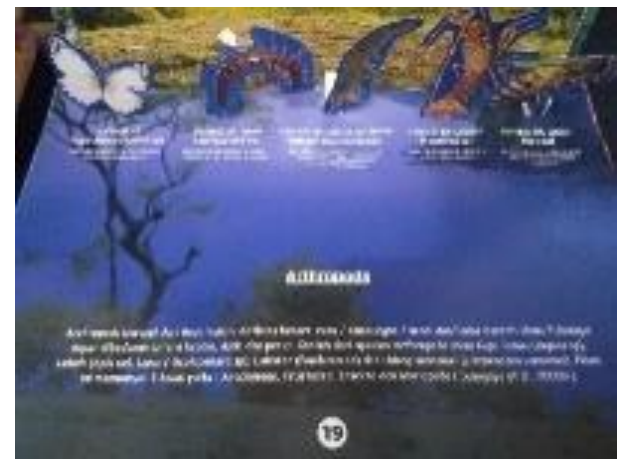

Tampilan materi pokok Arthropodha setelah direvisi

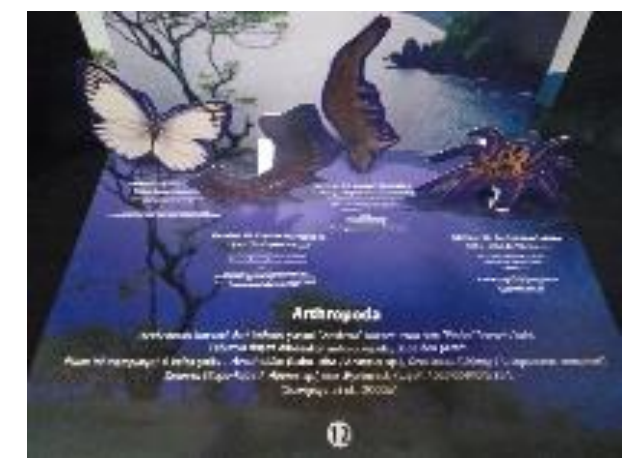

Gambar 4. Tampilan hasil revisi oleh guru IPA

d) Analisis skor angket respon siswa oleh siswa

Hasil perolehan kelayakan media pembalajaran pop-up book pada uji coba kelompok kecil sebanyak 11 siswa dan uji coba kelompok besar sebanyak 32 siswa. Hasil uji coba kelayakan media pop-up book dengan angket respon siswa pada uji coba kelompok kecil diperoleh nilai dengan rata-rata persentase tingkat pencapaian hasil uji coba kelompok kecil pada kriteria "Sangat layak" $(98,66 \%)$ sedangkan pada uji coba kelompok besar mendapatkan nilai kelayakan dengan rata-rata sebesar 92,91\% dengan kategori "Sangat layak". Berdasarkan hasil yang telah diperoleh pada uji coba kelompok besar dan kelompok kecil diperoleh tingkat pencapaian berada pada kualifikasi "Sangat layak" hal tersebut ditinjau dari persentase penilaian Sugiyono, (2016) yang menyatakan 
bahwa rentang persentase dikatakan "Sangat layak" jika berada pada rentang $80-100 \%$, jadi dapat disimpulkan media pembelajaran Pop-up Book layak digunakan dalam proses kegiatan pembelajaran. Hal ini sesuai dengan hasil penelitian yang dilakukan oleh (Masturah, Mahadewi, dan Simamora, 2018). Persentase tingkat pencapaian hasil uji coba lapangan berada pada kriteria "sangat baik" (90,08\%) sehingga media pop-up book layak digunakan sebagai media pembelajaran.

Hasil data angket respon siswa uji coba kelompok kecil terhadap media pop-up book dapat dilihat pada Gambar 5 dan hasil uji coba kelompok besar dapat dilihat pada Gambar 6.

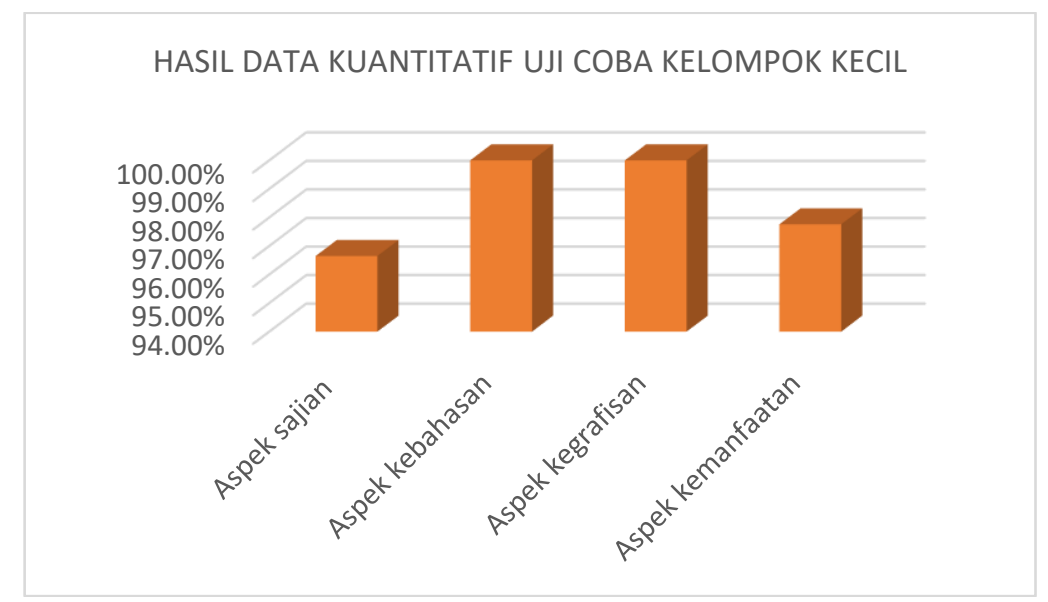

Gambar 5 Hasil Data Kuantitatif Uji Coba Kelompok Kecil

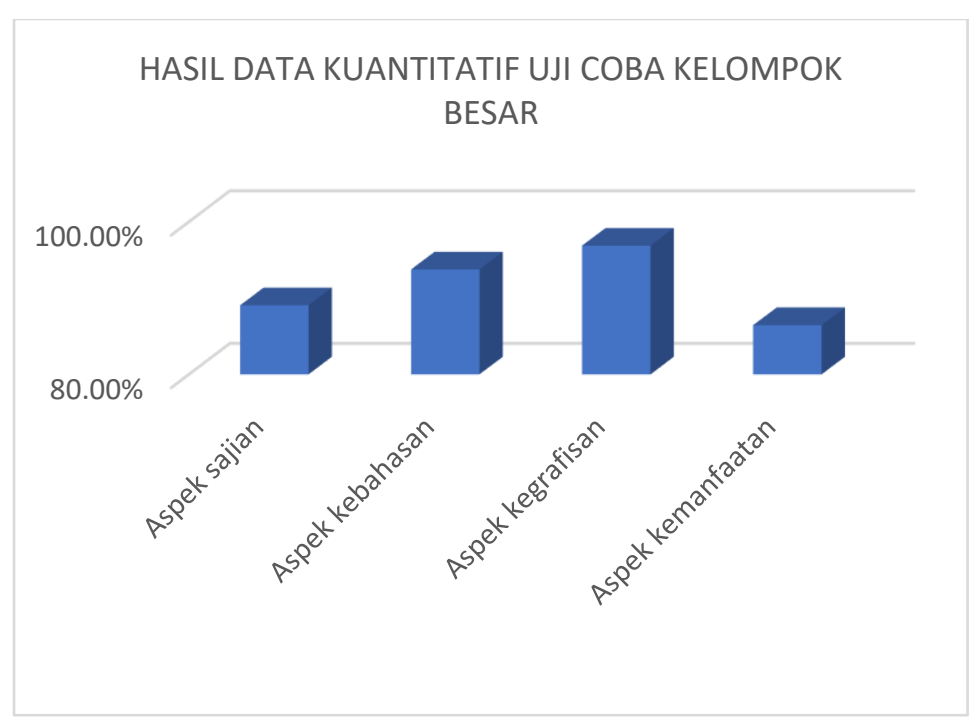

Gambar 6 Hasil Data Kuantitatif Uji Coba Kelompok Kecil

Media pembelajaran pop-up book yang dikembangkan dinyatakan layak digunakan sebagai media pembelajaran pada saat proses kegiatan belajar mengajar di sekolah. Hal tersebut terbukti karena dengan hasil dari uji ahli media, ahli materi, penilaian guru IPA dan respon siswa terhadap media pembelajaran pop-up book dengan rata-rata persentase tingkat pencapaian hasil uji coba kelayakan media pop-up book pada ahli media sebesar $85,7 \%$ (Sangat layak), ahli materi sebesar 69,4\% (Layak), penilaian guru IPA sebesar 95,25\% 
(Sangat layak), uji coba kelompok kecil pada siswa sebesar 98,66\% (Sangat layak), dan pada uji coba kelompok besar sebesar 92,1\%.

Hal ini sesuai dengan hasil penelitian Marhamah (2015), perancangan media pop-up book memiliki tingkat validitas sebesar $88 \%$ dan respon angket siswa sebesar $82 \%$ dan memiliki efektivitas $97 \%$ yang bermakna bahwa media pop-up book sangat layak digunakan sebagai media pembelajaran. Sesuai juga dengan hasil penelitian yang telah dilakukan oleh (Hawarya \& Warso, 2014) mengembangkan pop-up module pembelajaran biologi pada materi pencemaran dan pelestarian lingkungan untuk peserta didik SMA kelas X (sepuluh) dengan hasil penelitian dikategorikan baik dengan komponen penilaian berupa kelayakan isi, bahasa dan gambar, penyajian, dan kegrafisan atau tampilan.

\section{Tahap Disseminate (penyebarluasan)}

Tahap disseminate merupakan tahap akhir penelitian yang dilakukan yaitu tahap peneliti menyebarluaskan media Pop-up Book yang dikembangkan ke sekolah yang telah dituju. Media pembelajaran Pop-up Book yang sudah dikembangkan sudah dilakukan revisi perbaikan saran dan komentar dari ahli media, ahli materi, penilaian guru IPA dan respon siswa dan sudah layak digunakan sebagai media pembelajaran. Berdasarkan hasil penilaian dari ahli media, ahli materi, guru IPA dan respon siswa media pembelajaran pop-up book layak digunakan sebagai media pembelajaran yang digunakan dalam kegiatan pembelajaran.

\section{SIMPULAN}

Media pembelajaran pop-up book pada materi kingdom animalia yang sudah dikembangkan peneliti sudah layak digunakan dengan kategori 3 "Sangat layak" dan 1 kategori "layak", tetapi perlu dikembangkan lagi media pop-up book pada materi yang lain sehingga hasil penelitian ini dapat dilakukan penelitian lanjutan seperti PTK (Penelitian Tindakan Kelas) atau Quasi eksperimen.

\section{References}

Aprianty, V., Yeni, L. F., \& Wahyuni, E. S. (2016). Deskripsi Kesulitan Belajar Siswa pada Sub Materi Invertebrata Kelas X MAN 2 Pontianak. Jurnal Pendidikan Dan Pembelajaran Khatulistiwa, 5(12), 1-13. Retrieved from https://jurnal.untan.ac.id/index.php/jpdpb/article/download/17764/15134.

Budiarta, W.I. 2013. Pengembangan Multimedia Interaktif Model Addie Untuk Meningkatkan Motivasi Belajar Sejarah Siswa Kelas X-1 Semester Genap Di Sman 1 Sukasada, Buleleng, Bali. Jurnal Pendidikan Sejarah, Universitas Pendidikan Ganesha Singaraja, 2(1):1-12.

Desta setyawan, U. H. M. (2014). Penerapan Media Pop Up Book Untuk Meningkatkan Keterampilan Berbicara. Jurnal Didaktika Dwija Indria (SOLO), 2(11).

Hawarya, Y., \& Warso, A. W. D. D. (2014). Pengembangan pop-up module pembelajaran biologi pada materi pencemaran dan pelestarian lingkungan untuk siswa SMA kelas X. JUPEMASIPBIO (Jurnal Penelitian Mahasiswa Pendidikan Biologi), 1(1), 139-143. Retrieved from http://jupemasipbio.uad.ac.id/wp-content/uploads/2014/11/30.-NP_11A08003_YULISNA-H.pdf

Henno, I., \& Reiska, P. (2010). Difficulty of texts in upper-secondary school biology textbook - using concept maps for analyzing students new knowledge. Learning, 181-187.

Irwan. F, I. W. Santyasa, I M. \& Tegeh. 2014. Pengembangan Multimedia Interaktif Berbasis Self Regulated Learning dengan Model ADDIE untuk Meningkatkan Prestasi Belajar Seni Budaya Bagi Peserta didik Kelas VII SMP Negeri 3 Mendoyo. E-Journal Program Pascasarjana Universitas Pendidikan Ganesha Program Studi Teknologi Pembelajaran, 4:1-10. 
Khoirotun, A., Fianto, A. Y. A., \& Riqqoh, A. K. (2014). Perancangan buku pop-up museum Sangiran sebagai media pembelajaran tentang peninggalan sejarah. Jurnal Desain Komunikasi Visual, 2(1), 134-141. Retrieved from http://jurnal.stikom.edu/index.php/ArtNouveau/article/view/385.

Mawarni, E., Mulyani, B., \& Yamtinah, S. (2014). Penerapan Peer Tutoring Dilengkapi Animasi Macromedia Flash Dan Handout Untuk Meningkatkan Motivasi Berprestasi Dan Prestasi Belajar Siswa Kelas Xi Ipa 4 Sman 6 Surakarta Tahun Pelajaran 2013/2014 Pada Materi Kelarutan Dan Hasil Kali Kelarutan. Jurnal Pendidikan Kimia Universitas Sebelas Maret, 4(1), 29-37.

Marhamah. 2015. Perancangan dan Efektivitas Media Belajar Pop-up Book dengan Model ADDIE pada Mata Pelajaran Geografi Materi Vulkanisme Kelas VII SMP PKPU. Tesis tidak diterbitkan: PPs Universitas Syiah Kuala

Masturah, E. D., Mahadewi, L. P. P., \& Simamora, A. H. (2018). Pengembangan Media Pembelajaran Pop-Up Book pada Mata Pelajaran IPA Kelas III Sekolah Dasar. Jurnal EDUTECH Universitas Pendidikan Ganesha, 6(2), 212-221.

Permana, E. P., \& Sari, Y. E. P. (2018). Development of Pop Up Book Media Material Distinguishing Characteristics of Healthy and Unfit Environments Class III Students Elementary School. International Journal of Elementary Education, 2(1), 8-14. https://doi.org/http://dx.doi.org/10.23887/ijee.v1i1.13127

Sugiyono. (2016). Metode Penelitian Pendidikan. Bandung: Alfabeta.

Thiagarajan, S., Semmel, S. D., \& Semmel, I. M. (1974). Instructional Development of Expectional Children (M. Minneapolis, ed.). Leadership Training Institue/Special Education: University of Minnesota.

Henno, I., \& Reiska, P. (2010). Difficulty of texts in upper-secondary school biology textbook - using concept maps for analyzing students new knowledge. Learning, 181-187.

Iizuka, S., Endo, Y., Mitani, J., Kanamori, Y., \& Fukui, Y. (2011). An interactive design system for pop-up cards with a physical simulation. Visual Computer, 27(6-8), 605-612. https://doi.org/10.1007/s00371-011-0564-0

Irwan, F., Santyasda, I. W., \& Tegeh, I. M. (2014). Pengembangan Multimedia Interaktif Berbasis Self Regulated Learning dengan Model ADDIE untuk Meningkatkan Prestasi Belajar Seni Budaya bagi Siswa Kelas VII SMP Negeri 3 Mendoyo. E-Journal Program Pascasarjana Universitas Pendidikan Ganesha, 4(1), 1-10.

Mawarni, E., Mulyani, B., \& Yamtinah, S. (2014). Penerapan Peer Tutoring Dilengkapi Animasi Macromedia Flash Dan Handout Untuk Meningkatkan Motivasi Berprestasi Dan Prestasi Belajar Siswa Kelas Xi Ipa 4 Sman 6 Surakarta Tahun Pelajaran 2013/2014 Pada Materi Kelarutan Dan Hasil Kali Kelarutan. Jurnal Pendidikan Kimia Universitas Sebelas Maret, 4(1), 29-37.

Shita, anggit., \& Dkk. (2013). PENGEMBANGAN MEDIA Pembelajaran Buku Pop-Up Wayang Tokoh Pandhawa Pada Mata Pelajaran Bahasa JawaKelas V SD. Journal of Chemical Information and Modeling, 53(9), 1-16.

Zainorrahman, Z., Azizah, L. F., \& Kadarisman, K. (2019). PENGEMBANGAN MEDIA BERBASIS POP UP BOOK UNTUK PEMBELAJARAN IPA DI MTs RAUDHATUT THALIBIN. Alpen: Jurnal Pendidikan Dasar, 2(2), 99-106. https://doi.org/10.24929/alpen.v2i2.21

Journal of Learning and Instructional Studies (2021), 1(1), 25-36 